\title{
O mundo do trabalho para os concluintes de um curso de Direito
}

\section{The labor market for law graduates}

\author{
Maria Aparecida Silva Mariosa ${ }^{1}$ \\ Mírian dos Santos ${ }^{2}$
}

\section{Resumen:}

El artículo que sigue pretende desarrollar una reflexión sobre la situación de la educación superior, a partir de la experiencia obtenida de un estudio realizado con estudiantes egresados de la Escuela de Derecho del Sur de Minas - MSDS, ubicada en la ciudad de Pouso Alegre, MG, Brasil. La intención principal de este artículo es responder a las siguientes preguntas: ¿Qué características tiene el estudiante que está terminando su formación en la Facultad de Derecho del Sur de Minas? y ¿cuáles son sus perspectivas en el mercado laboral?

El presente artículo tiene dos objetivos como ejes: el primero es conocer cómo el egresado de la Facultad de Derecho de Minas del Sur evalúa su proceso de formación, y, el segundo busca identificar los dilemas, retos y expectativas que la carrera de Derecho ha promovido en su proyecto de vida personal y profesional. Para lograr estos objetivos, se exponen en el texto las ideas relevantes de autores que colaboran con la definición y problematización de la enseñanza del Derecho y con la importancia de concebir un perfil profesional del Derecho.

Palavras clave: Enseñanza del Derecho, formación profesional, inclusión laboral.

\begin{abstract}
:
This article attempts to reflect upon higher education using evidence collected for a study where students graduated from Sul de Minas Law School participated (Pouso Alegre, Brasil). The article seeks to answer the following questions: Which are the main characteristics of students that are in the final stages of their studies in Sur de Minas School of Law? And, which chances do they have in the labor market?

The article has two main objectives. First, it seeks to learn how do students graduated from the School of Law of Sul de Minas evaluate the legal training they received. Second, the article pursue to identify dilemas, challenges and expectations that legal training has promoted and how this has impacted students' personal and professional lives. In order to accomplish these objectives, the article presents relevant ideas from authors that have worked on the definition and the formulation of questions related to teaching law and who deal with the importance of elaborating a clear professional profile for law graduates.
\end{abstract}

Keywords: Legal training, professional training, labor market inclusion.

\footnotetext{
${ }^{1}$ Universidade do Vale do Sapucaí (Univás) Pouso Alegre/ MG/Brasil Faculdade de Direito do Sul de Minas Pouso Alegre/MG/Brasil cmariosa@uol.com.br

${ }^{2}$ Universidade do Vale do Sapucaí (Univás) Pouso Alegre/ MG/Brasil Faculdade de Direito do Sul de Minas Pouso Alegre/MG/Brasil miriandossantos@ hotmail.com
} 


\section{Introdução}

Segundo o dicionário do Aurélio (2010), dilema é situação embaraçosa com duas saídas difíceis ou penosas. É assim que podemos ver os alunos do último ano de vários cursos de graduação que não sabem o caminho a ser tomado para a sua realização profissional. E os alunos do curso de Direito não fogem a isso. Diante disto surge uma grande pergunta: em um curso de Direito, quais seriam as aspirações de um recém-bacharel? De pronto a resposta já nos afigura: passar num concurso para juiz, promotor, delegado e outros cargos públicos. Isto porque são empregos que oferecem remuneração alta e aposentadoria com o salário que o profissional tinha no ano em que se aposentou. Por outro lado, encontramos uma quantidade relativamente grande de concluintes que excede a demanda do mercado de trabalho e não consegue atuar na área.

Refletindo sobre a situação dos cursos superiores, mas com olhar na Faculdade de Direito do Sul de Minas - FDSM, situada na cidade de Pouso Alegre, MG, Brasil, nossa intenção neste trabalho é responder aos seguintes questionamentos: Quem é o aluno que está concluindo o curso de Direito na Faculdade de Direito do Sul de Minas e quais são as suas perspectivas no mundo do trabalho?

Buscando respostas a essas questões, nossa proposta é um estudo sobre o assunto, que é de relevância não só para a Instituição em foco, mas também para os que militam nesta área em todo contexto social que se acha carente de Justiça.

Para melhor entendermos as idéias colocadas pelos formandos, entrevistamos 97 concluintes do Curso de Direito da FDSM, no ano de 2010. Eles deveriam responder a questões que direcionavam a nossa pesquisa. As questões se encontram no anexo 1.

Aplicamos o questionário com a anuência da direção e dos alunos. Fizemos a análise dos dados, procurando observar as idéias do concluinte, seu dilema diante de um diploma na mão e sem saber o que fazer com ele, enfim as expectativas futuras.

Portanto, nosso objetivo é conhecer como o concluinte da Faculdade de Direito do Sul de Minas avalia seu processo de formação e identificar os dilemas, desafios e expectativas que o curso promove em seu projeto de vida pessoal e profissional. Mas antes de realizarmos a pesquisa com os alunos do $5^{\circ}$ ano do curso de Direito, tivemos necessidade de fundamentar nosso trabalho, amparando-nos em autores que analisam o ensino do Direito no Brasil e destacam o perfil do profissional do Direito.

\section{A responsabilidade do formador do bacharel em Direito}

Na década de 1990, houve uma grande expansão do número de vagas nas faculdades, principalmente no curso noturno para atender o aluno-trabalhador, por consequência do elevado número de alunos que terminavam o ensino médio. Aproximadamente dez anos depois dessa proliferação de vagas, Rodrigues e Junqueira (2001) já nos alertavam que;

Deve-se planejar a expansão com qualidade, evitando-se o fácil caminho da massificação. [...] Ressalte-se a expansão de vagas no período noturno, considerando que as universidades, sobretudo as federais, possuem espaço para este fim, destacando a necessidade de se garantir o acesso a laboratórios, bibliotecas e outros recursos que assegurem ao aluno-trabalhador o ensino 
de qualidade a que tem direito nas mesmas condições de que dispõem os estudantes do período diurno. $^{3}$

Por outro lado, a Instituição de Ensino Superior (IES) tem a sua parcela de contribuição no desenvolvimento do homem como ser criativo, autônomo, responsável, ético, competente em sua área de atuação e com o olhar no bem- estar social. Portanto, cabe a ela estar sempre repensando o processo de atualização, dando sua contribuição valiosa para a formação "desse homem" que precisa se educar constantemente, já que a educação tem caráter permanente, e o mundo atual está mudando numa velocidade incrível. Mas será que a graduação está a desempenhar realmente o seu papel, contribuindo na formação "desse homem”?

Como educadores, somos cúmplices da construção de um ideal de educação que permita ao Brasil ter jovens bem formados e cientes do seu papel de cidadão, diante do destino da sociedade, em nível de pátria e de mundo.

Conforme o art. $2^{\circ}$ da Nova LDB 9.394/96, a educação brasileira deve ser norteada por princípios humanísticos e [...] "tem por finalidade o pleno desenvolvimento do educando, seu preparo para o exercício da cidadania e sua qualificação para o trabalho". Nesta visão, o homem, por intermédio da educação escolar, deve vincular-se ao mundo do trabalho e à prática social.

Segundo o que preconiza o artigo 43, do Cap. IV, da LDB 9394/96, a Educação Superior tem por finalidade II - formar diplomados nas diferentes áreas de conhecimento, aptos para a inserção em setores profissionais e para a participação no desenvolvimento da sociedade brasileira, e colaborar na sua formação contínua.

O profissional da carreira jurídica, inusitadamente, depara-se com situações em que precisará de formação ética e técnica para orientar seus procedimentos.

Morin (2000) considera a educação um processo de formação para a vida e diz: "O conhecimento do mundo como mundo é necessidade ao mesmo tempo intelectual e vital" ". Para reconhecer e conhecer os problemas do mundo é necessário que haja a reforma do pensamento. $\mathrm{O}$ advogado tem como matéria prima de seu trabalho "o problema". Isto porque a ciência do Direito tem como objeto uma prática voltada para a solução dos conflitos.

Ribeiro Júnior (2001) afirma que a falta de condições teóricas da maioria dos juristas se deve ao fato de eles, não tomarem conhecimento dos novos subsídios que a ciência do Direito vem recebendo na Europa e nos Estados Unidos, abrindo uma nova delimitação de seu estatuto teórico e político. A concepção dogmática da ciência do Direito, mesclada de jusnaturalismo com positivismo e idealismo jurídico, a princípio está comprometida com a sociedade que está em crise.

A corrente do jusnaturalismo, baseada na Teoria do Direito Natural é muito antiga, sendo definido por Gusmão (1996) da seguinte forma: O jusnaturalismo é a corrente tradicional do pensamento jurídico, que defende o direito natural, considerando-o superior ao direito positivo. Corrente que se tem mantido de pé apesar das várias crises por que tem passado, e que, apesar de

\footnotetext{
${ }^{3}$ RODRIGUES, Horácio Wanderley; JUNQUEIRA, Eliane Botelho, "Ensino do direito no Brasil”, 2002 , p.348.

${ }^{4}$ MORIN, Edgard. Os sete saberes necessários à educação do futuro, 2000, p. 36.
} 
criticada por muitos, mantém-se fiel ao menos a um princípio comum: a consideração do direito natural como direito justo por natureza, independente da vontade do legislador, derivado da natureza humana (jusnaturalismo) ou dos princípios da razão (jusracionalismo), sempre presente na consciência de todos os homens 5 .

O positivismo jurídico é caracterizado pelo fato passível de estudo científico e o idealismo jurídico pode ser entendido como a doutrina dos ideais do comportamento humano e das criações culturais, direito e estado.

Hoje se constata que a o ensino jurídico precisa ser mudado, e isto se deve ao fato de que a realidade em que atuará o profissional da área é complexa e está em permanente transformação.

Desta forma, foram definidas diretrizes para o ensino na área, que privilegiam uma formação humanística, técnico-científica e prática que dê condições à compreensão da complexidade do fenômeno jurídico e a sua produção cultural num contexto de transformações sociais.

Não podemos deixar de ressaltar o trabalho que a Ordem dos Advogados do Brasil vem fazendo no tocante às exigências relacionadas ao ensino jurídico, desde 1991, quando foi criada a Comissão de Ensino Jurídico (CEJ), tendo como um dos objetivos a atualização dos cursos jurídicos, observando os impasses que afetam a prática social e teórica de todos os operadores jurídicos.

A Comissão de Ensino Jurídico cuidou precisamente de indicar parâmetros para uma contextualização dos projetos didático-pedagógicos a ela submetidos e de estabelecer os seus referenciais, de forma a visualizar o perfil e habilidades que os cursos jurídicos intentam formar.

O sistema de referências criado objetivou formar um perfil que permitisse orientar o processo de formação de opinião sobre os cursos jurídicos e de fundamentação dos pareceres que oferecem subsídios sobre a criação e recredenciamento.

O curso jurídico apresenta uma necessidade social devido à sua própria estrutura que lida com o social na contextualização, interagindo com as demandas sociais e de mercado em transformação. As inovações pedagógicas dentro do curso jurídico enfrentam inúmeros questionamentos, dentre os quais os relacionados com a formação dos professores. A criação de um diálogo aberto dentro da escola apresenta uma oportunidade de enfrentamento dos problemas, com soluções de interesse comum, influenciando o processo de aprendizagem.

Vivemos um momento de grande expansão do ensino jurídico e a Comissão do Ensino Jurídico, observando os problemas oriundos dessa expansão e da demanda de atualização constante, também aponta o diálogo como uma porta aberta para novos caminhos.

Outro questionamento a ser considerado diz respeito à requalificação do sistema de ensino jurídico no Brasil. A OAB deu a este movimento sua contribuição, no tocante a procedimentos para a criação e reconhecimento de cursos.

\footnotetext{
${ }^{5}$ GUSMÃO, Paulo Dourado de. Introdução ao estudo do direito. 1996, p.385.
} 
Se indagarmos sobre os motivos pelos quais a OAB organiza o agir da atividade do operador ${ }^{6}$ do Direito, temos que considerar que ela coordena o agir da única atividade profissional com reconhecimento constitucional expresso: "O advogado é indispensável à administração da justiça ..."7.

Para balizar as diretrizes curriculares do ensino jurídico para a área do Direito, contamos com a Portaria $\mathrm{n}^{\mathbf{0}} 1.886$, de 30 de dezembro de 1994, publicada pelo Ministro Murílio de Avellar Hingel, do Ministério de Estado da Educação e do Desporto. No entanto, questiona-se sobre sua validade, pois ela foi publicada antes da Lei de Diretrizes e Bases da Educação, Lei nº 9.394 de 20 de dezembro de 1996. O conteúdo da Portaria privilegia a pesquisa e a iniciação científica, bem como as atividades complementares.

Assim pressupõe-se que o Curso Jurídico deve proporcionar uma sólida formação técnicojurídica e sociopolítica aos alunos, preocupando-se em desenvolver certas competências e habilidades imprescindíveis ao operador do Direito.

\section{Problematizando o curso de direito}

Ao problematizarmos o Ensino Jurídico no Brasil, é nossa intenção abordarmos alguns pontos relevantes, para melhor entendermos o que se passa na Faculdade de Direito do Sul de Minas. O aluno de Direito, na instituição onde atuamos, com raras exceções, busca o curso para assegurar algum emprego que já tem, ou ter acesso na carreira que vem atuando. Isso podemos constatar por meio de pesquisa realizada com egressos da Faculdade de Direito do Sul de Minas, onde a maioria realizou o curso no período noturno ${ }^{8}$.

Melo Filho ${ }^{9}$ comenta sobre a institucionalização do curso noturno, apresentando inicialmente que o aluno, desde o vestibular, já deve fazer sua opção pelo turno almejado para cursar o Direito. Caso contrário, ao longo do curso, há um esvaziamento no período diurno, causado pela procura do aluno-trabalhador que, devido às circunstâncias, busca o curso noturno. Este fato ocorre, também, na FDSM.

Vale a observação de que o aluno do curso diurno tem um perfil diferenciado do aluno do curso noturno. São alunos mais jovens que desejam ingressar na carreira como operadores do Direito, prestando concurso para ocuparem um cargo público. Observamos que há uma crise na formação do jurista e na ciência do Direito, colocada por Herkenhoff como decorrente: [...] de problemas pertinentes ao conjunto da sociedade brasileira e ao conjunto dos problemas da educação no País; de questões ligadas ao conjunto da educação universitária; e ainda de aspectos específicos ligados ao ensino do Direito. A crise na Ciência do Direito é consequência de uma visão conservadora, divorciada da realidade histórica, míope, acrítica do saber jurídico ${ }^{10}$.

\footnotetext{
${ }^{6}$ Termo que indica a atuação do bacharel em Direito.

${ }^{7}$ BRASIL. Constituição da República Federativa do Brasil: promulgada em 5 de outubro de 1988, 2002, p. 87.

${ }^{8}$ MARIOSA, Maria Aparecida Silva. Perfil de ingressantes /2002. 2002.

${ }^{9}$ MELO FILHO, Álvaro. "Currículo jurídico - um modelo atualizado", 1996a, p.61

${ }^{10}$ HERKENHOFF, João Batista, OAB - Ensino jurídico. In OAB, Conselho Federal da Ordem dos Advogados do Brasil. OAB Ensino Jurídico: Diagnóstico, perspectivas e propostas. 1996, p.121.
} 
A formação do jurista fica comprometida por vários aspectos que a educação universitária não oferece, tais como: existência de qualquer orientação vocacional no Ensino Superior, pois os jovens escolhem o curso a fazer por conta própria; a unificação de vestibulares que obriga a todos estudarem as mesmas disciplinas, mesmo aquelas que não têm relação alguma com o curso. Mas já podemos encontrar, atualmente, algumas IES que já estão adotando outros critérios na seleção de matérias para o vestibular, que serão de maior utilidade para o futuro acadêmico. A Faculdade de Direito do Sul de Minas já adota para o vestibular, somente provas de Português, Redação, História, Geografia e uma língua estrangeira (inglês ou francês).

O Curso de Direito tem uma linha de tradição positivista, enraizada no pensamento brasileiro, desencorajando o pensamento crítico, formando o jurista muito técnico a serviço da conservação das estruturas sociais. Não existe uma sincronia na coordenação horizontal e vertical nos currículos que não são enriquecidos por uma perspectiva multidisciplinar ${ }^{11}$.

A crise do Ensino Jurídico no Brasil é agravada pela inadequação entre formação sócioprofissional e distribuição sócio-ocupacional. Para Ribeiro Júnior "a ciência do Direito tem como objeto as práticas do Direito, principalmente aquelas voltadas à solução de conflitos. A legitimação do Direito depende de sua capacidade de trabalhar os problemas político-sociais" "12 Nesse sentido, Cury (2000, p. 149-50) mostra que os cursos de Direito deverão ter a preocupação de habilitar o bacharel para uma atuação crítica e reflexiva na sociedade.

O ensino jurídico ainda possui um currículo muito engessado e pouco se abre a novos direitos. A tentativa de ampliação ou da implantação de uma visão progressista no âmbito do Direito é bastante limitada a números restritos.

Em geral, a Faculdade não oferece as condições ao aluno de sair preparado para o exercício do Direito. Há que se estabelecer uma prática em que o estágio deva ser cumprido com processos reais cuja riqueza da realidade é que irá dar as condições para o operador do Direito poder trabalhar.

Herkenhoff afirma: “O próprio povo, sobretudo os das classes oprimidas são os agentes e os principais protagonistas do Direito, no seu grito de justiça"13. Portanto, o aluno do Curso de Direito, necessariamente, para poder aprender a trabalhar, deverá estar em contato com o povo em seu contexto.

Apesar de afirmarmos com frequência que há necessidade de um novo Direito, observamos, que o conhecimento reproduzido no ensino desta área do saber, ainda se encontra fora da realidade social e científica contemporânea.

Sem querer generalizar, vemos que os programas usados nos cursos de Direito orientam-se por uma linha de conformismo e passividade. Os métodos de ensino usados em salas de aulas são os mais convencionais. Mas também encontramos professores que buscam aprimorar seus métodos,

\footnotetext{
${ }^{11}$ HERKENHOFF, João Batista, Ibíd., p.122

12 RIBEIRO JÚNIOR, João. A formação pedagógica do professor de Direito: Conteúdos e alternativas metodológicas para a qualidade do ensino do Direito, Campinas, SP, Papirus, 2001, p.26

${ }^{13}$ HERKENHOFF, João Batista, Ibíd., p.125
} 
adotando novas experiências nas mais diversas cadeiras do currículo. Não podemos deixar de lado as salas que são bastante numerosas, dificultando o trabalho do professor na busca de aplicar novas técnicas de ensino e aprendizagem.

Melo Filho aponta no 'quadro patológico' do ensino do Direito “[...] sobrecarga de alunos por semestre letivo e turmas de 60, 70 ou até 80 alunos, resultante, sobretudo, da indivisão entre turnos diurno e noturno, este último jamais institucionalizado" ${ }^{\text {.14. }}$.

A institucionalização do curso noturno, explicada por Melo Filho é no sentido de que, ao prestar o vestibular, o acadêmico já deve indicar o turno que vai cursar, para evitar o "esvaziamento" do curso diurno e, em contrapartida, o "inchaço" do noturno, comprometendo a qualidade do aproveitamento das aulas ministradas à noite. Para que não ocorra tal fato, as faculdades tomam o cuidado de só transferirem o aluno de um turno para outro se houver a vaga, pois cada turma tem um limite de alunos pré-estabelecido com aprovação da autoridade competente.

As diretrizes do ensino jurídico precisam ser repensadas, para que a formação do operador do Direito não continue tendo uma visão do ângulo dogmático-normativo, que o conduz ao legalismo. O conhecimento jurídico não pode ser baseado em abstrações que se chocam com a justiça; o procedimento jurídico se dirige a valores do grupo, afirmando a necessidade de ser baseado no contexto.

O corpo docente, geralmente, é formado por profissionais com boa bagagem de conhecimento, mas sem o devido preparo para o exercício do magistério, e ainda "horista", por não poder se dedicar exclusivamente às atividades que envolvem a função de professor. Por mais paradoxal que pareça, "o ensino do Direito aparece como um dos instrumentos que, dentro de uma sociedade plural, complexa e em crise, busca omitir e encobrir as diferenças sociais, econômicas, políticas e culturais existentes"

O ensino do Direito, inicialmente, era aprendido pela imitação dos líderes, que "ensinavam" o Direito ao fazê-lo obedecido. A filosofia do Direito apresenta a fase dos textos jurídicos e passa a imaginar uma ciência do Direito. O ensino jurídico, com seu caráter pragmático como atualmente se apresenta, está apegado ao Direito positivo e à jurisprudência.

O ensino do Direito acumula informações, é um simplificador da realidade, baseado na arte da exposição onde a metodologia de ensino predominante é a aula expositiva e o código comentado. O método de abordagem é o dedutivo e raramente usado o indutivo. A premissa maior é a norma jurídica, a premissa menor é o fato, e a conclusão é a solução de direito para o caso concreto. $\mathrm{O}$ ensino do Direito deve estar pautado no despertar da consciência jurídica conectado com a realidade social na qual vai ser utilizado e no conhecimento de um novo Direito contextualizado com a sociedade concretamente existente, cujo ensino esteja em consonância com as novas práticas exigidas pela modernidade ${ }^{16}$.

\footnotetext{
${ }^{14}$ MELO FILHO, Álvaro, Ibíd., p.56.

${ }^{15}$ RIBEIRO JÚNIOR, João, Ibíd., p.52.

${ }^{16}$ RIBEIRO JÚNIOR, João, Ibíd.
} 
É preciso repensar o ensino tradicional proposto por diversas Faculdades de Direito, a fim de que não ocorra a falência do ensino jurídico. Faria ${ }^{17}$ enfatiza que uma das causas da morosidade da justiça é o acúmulo dos processos provocado por:

Incapacidade funcional e burocrática do Judiciário de tratar com agilidade e eficiência os milhares de novos processos. [...] cargos estão vagos porque nossos tribunais não têm conseguido preenchê-los, apesar dos inúmeros concursos públicos promovidos ao longo destes últimos anos. [...] O principal motivo está na péssima formação dos bacharéis que se inscrevem nesses concursos.

Faria $^{18}$ faz referência, em artigo publicado na Revista da Procuradoria Geral do Estado, em junho de 1991, que o desembargador Aniceto Lopes Aliende, então presidente do Tribunal de Justiça de São Paulo, apresentou os resultados de seis concursos para cem vagas, e foi o seguinte:

155 concurso: inscritos: 1.676 / aprovados: 48

156 ${ }^{\circ}$ concurso: inscritos: 1.671 / aprovados: 43

$157^{\circ}$ concurso: inscritos: $2.060 /$ aprovados: 34

158 concurso: inscritos: 2.008 / aprovados: 45

159 concurso: inscritos: 1.975 / aprovados: 59

160 concurso: inscritos: 1.450 / aprovados: 57

Apesar dos anos que já se passaram, os números de aprovados em concursos continuam alarmantes em proporção ao número de candidatos que se submetem às provas. Dos 27.324 candidatos ao Exame de ORDEM da OAB/MG de 2002, 15.650 foram aprovados, representando 57,28\%.(Jornal do Advogado/ Belo Horizonte - MG - Ano XXVI, no 167 224, p. 17, Janeiro, 2003).

Isto demonstra que as provas aplicadas no Exame da ORDEM da OAB/MG não retratam o que o aluno vem aprendendo na IES.

\section{Condições para solucionar problemas}

Em pleno século XXI, o modelo clássico do Direito Positivo ocidental já não tem mais sentido; é preciso repensar, romper com a dogmática lógico-formal ainda reinante nas Faculdades de Direito, com seu ensino tradicional, a fim de proporcionar as condições e os pressupostos necessários para um conhecimento jurídico realmente crítico, que discuta e critique a sua eficácia e a sua legalidade.

Voltando a um passado recente, falemos sobre San Tiago Dantas que até sua morte, em 1965, permaneceu no Conselho de Pesquisa Jurídica da Casa Rui Barbosa onde iniciou as primeiras experiências sobre a questão da pesquisa jurídica, buscando aprofundar estudos fora dos autos e da casuística. San Tiago introduziu a discussão sobre o problema do método da reflexão jurídica, seu aprendizado e desenvolvimento.

A mensagem deixada por San Tiago foi: como se deve ensinar Direito ${ }^{19}$

\footnotetext{
${ }^{17}$ FARIA, José Eduardo. O ensino jurídico1996a, p.168.

${ }^{18}$ FARIA, José Eduardo, Ibíd., p.169
} 
O que se deve ensinar, em Direito sabemos: deve-se ensinar o Código, as leis, a doutrina e sua interpretação, mas nunca se sabe como ensinar o Direito, ou mesmo as formas diferentes de se ensinar o Direito. Bastos citando San Tiago, explica: "a base do aprendizado é o desenvolvimento do raciocínio jurídico, ensinar o aluno a pensar juridicamente, a refletir juridicamente sobre os fatos e situações ou sobre a própria lei” ${ }^{20}$. A formação do advogado está em aprender a pensar o Código de tal maneira que a reflexão jurídica seja pensada em função da lógica jurídica, da hermenêutica, dos recursos sociológicos e de dinâmica da própria sociedade.

O currículo de 1972 restringiu a estrutura curricular a âmbitos teóricos, filosóficos e humanistas, introduzindo como pré-requisito a Sociologia, a Economia e manteve a Introdução do Estudo do Direito, com uma estrutura de curso positivista, inovando na criação de habilitações e com disciplinas opcionais, demonstrando claramente que o advogado deve ter uma formação especializada, além da formação interdisciplinar básica e profissionalizante de Direito Positivo.

A formação de advogados, no Brasil, a partir de 1972, apresenta um crescimento muito grande, mas com graves problemas de natureza estrutural. Houve o crescimento dos cursos sem que houvesse incentivo aos cursos de mestrado e formação de docentes na área. Até os dias de hoje, a formação de docentes é situação considerada uma das mais graves do ensino superior brasileiro, conforme Bastos $^{21}$ demonstra que os cursos de Medicina, ou os cursos de Engenharia têm uma relação de 25 (vinte cinco) alunos para um mestre-doutor, o curso de Direito tem uma relação de 500 (quinhentos) alunos para um mestre-doutor.

Bastos aponta que: A Faculdade de Direito precisa retomar o seu lugar de reflexão, e não apenas de ocupação de espaços institucionais na vida da sociedade brasileira moderna. As sociedades que não incentivam a formação do pensamento jurídico e desenvolvimento das instituições políticas serão sempre simulação de sociedades democráticas ${ }^{22}$.

A pesquisa jurídica ainda não é vista por muitos alunos e professores do curso de Direito como importante instrumento de formação aberta e plural do advogado, associada à base da reflexão na busca de solução de problemas.

A solução de problemas é o cotidiano da vida do advogado. O ensino de Direito deve estimular o aluno a resolver problemas com base nas leis e no conhecimento jurídico interpretativo. Os advogados são profissionais de problemas humanos em diversos âmbitos; são profissionais destinados e voltados para solucionar problemas. Ninguém procura um advogado a não ser para resolver problemas.

As propostas desse perfil de curso de Direito tomaram corpo com a publicação da Portaria 1.886/94 que apresenta um novo currículo, as novas diretrizes para o curso, com a preocupação de formar profissionais aptos a responder às demandas da cidadania e do desenvolvimento econômico e científico.

\footnotetext{
${ }^{19}$ BASTOS, Aurélio Wander. O ensino jurídico no Brasil e as suas personalidades históricas -uma recuperação de seu passado para reconhecer seu futuro, 1997, p.47

${ }^{20}$ BASTOS, Aurélio Wander, Ibíd., p.48

${ }^{21}$ BASTOS, Aurélio Wander, Ibíd., p.52

${ }^{22}$ BASTOS, Aurélio Wander, Ibíd., p.53
} 


\section{A FDSM e a preocupação com o profissional do Direito}

Apesar das dificuldades encontradas para projetar o profissional do futuro de uma sociedade em mudança acelerada, o profissional do Direito deve apresentar o perfil delineado para o graduando do referido curso, que serve como subsídio para o profissional que se pretende alcançar, conforme a Portaria $\mathrm{n}^{\circ}$ 526, de 09 de abril de 1997, do Ministério da Educação e Cultura e do Desporto, aprovado e divulgado.

a) formação humanística, técnico-jurídica e prática indispensável à adequada compreensão interdisciplinar do fenômeno jurídico e das transformações sociais;

b) senso jurídico e ético-profissional, associado à responsabilidade social, com a compreensão da causalidade e finalidade das normas jurídicas e da busca constante da libertação do homem e do aprimoramento da sociedade;

c) capacidade de apreensão, transmissão crítica e produção criativa do Direito, aliada ao raciocínio lógico e à consciência da necessidade de permanente atualização, não só técnica, mas como processo de educação ao longo da vida;

d) capacidade para equacionar problemas e buscar soluções harmônicas com as exigências sociais;

e) capacidade de desenvolver formas extrajudiciais de prevenção e solução de conflitos individuais e coletivos;

f) visão atualizada de mundo e, em particular, consciência solidária dos problemas de seu tempo e de seu espaço.

O perfil desejado para o formando do curso de Direito deverá possibilitar que o aluno adquira as seguintes competências e habilidades, apontadas no Art. $4^{\circ}$ da Resolução no 9, de 29 de setembro de 2004, do Conselho Nacional de Educação - CNE, e Câmara de Educação Superior - CES:

I- leitura, compreensão e elaboração de textos, atos e documentos jurídicos ou normativos, com a devida utilização das normas técnico-jurídicas;

II- interpretação e aplicação do Direito;

III- pesquisa e utilização da legislação, da jurisprudência, da doutrina e de outras fontes do Direito;

IV- adequada atuação técnico-jurídica, em diferentes instâncias, administrativas ou judiciais, com a devida utilização de processos, atos e procedimentos;

V-correta utilização da terminologia jurídica ou da Ciência do Direito;

VI- utilização do raciocínio jurídico, de argumentação, de persuasão e de reflexão crítica;

VII-julgamento e tomada de decisões; e

VIII- domínio de tecnologias e métodos para permanente compreensão e aplicação do Direito.

Há uma preocupação em formar bacharéis em Direito, generalistas que possam habilitar às mais diversas carreiras jurídicas. Tal perfil tem sido mantido até os dias atuais, embora já possam ser 
notados alguns traços de mudança, especialmente com a implantação e o desenvolvimento da pesquisa e extensão.

Partindo de uma estrutura curricular moderna, fixada em sintonia com os movimentos jurídicos atuais, a FDSM tem a intenção de proporcionar aos seus alunos condições de adquirirem formação humanística, técnico-jurídica e prática, procurando conduzir o acadêmico à compreensão dos fenômenos jurídicos e transformações sociais.

O profissional do Direito afigura-se como agente fundamental na possibilidade de realização, não só dos direitos e garantias individuais do cidadão do país, mas também na conquista de uma sociedade justa.

Ele deverá possuir senso ético inerente à responsabilidade social em razão de sua importância para o país, com pleno conhecimento da causalidade e finalidade das normas jurídicas, o que implica em visão crítico-filosófica do Direito.

Deverá, ainda, ser capaz de desenvolver formas extrajudiciais de prevenção e solução de conflitos individuais e coletivos. Acima de tudo, deverá crer no Direito e na Justiça como instrumentos capazes de promover a paz, a harmonia e a ordem social.

Para que estes objetivos possam ser atingidos e tais habilidades adquiridas, são necessárias inúmeras mudanças, dentre as quais o uso de estratégias pedagógicas que os realizem. Em síntese, relacionamos algumas estratégias elencadas no Projeto Pedagógico da FDSM ${ }^{23}$, que estão sintetizados a partir do estabelecimento de competências e habilidades presentes no referido documento:

- habilidades relativas a um bom manejo dos instrumentos linguísticos, consubstanciadas na capacidade de leitura, compreensão e elaboração de textos e documentos: aulas teóricas de língua portuguesa e trabalhos de interpretação de textos, bem como a elaboração de textos e peças processuais e legislativas, visando a colocar o aluno em contato com a prática que envolve as questões abordadas teoricamente em sala de aula;

- habilidades relativas à compreensão hermenêutica do Direito: abordagens no tocante à hermenêutica, à correta compreensão das fontes do Direito e dimensão ideológica da elaboração normativa, técnicas de argumentação jurídica e domínio de questões de lógica jurídica;

- habilidades relacionadas à pesquisa e compreensão do Direito, através de mecanismos pedagógicos de metodologia científica e técnicas de pesquisa;

- competência para o agir e tomada de decisões no âmbito das funções de operador do Direito, através de uma constante inter-relação entre teoria e prática.

Essas são algumas habilidades e competências que o profissional do Direito deve adquirir para bem exercer a função de promover a justiça.

\footnotetext{
${ }^{23}$ PROJETO PEDAGÓGICO DA FACULDADE DE DIREITO DO SUL DE MINAS, 2009, pp.25-26
} 


\section{A voz dos alunos concluintes do curso de direito da FDSM}

Responderam ao questionário um total de 97 alunos representando 51,87\% do total de matriculados na quinta série. $\mathrm{O}$ instrumento usado para a coleta de dados se encontra no anexo.

O tratamento dos dados coletados foi bem diversificado e, segundo o tipo de respostas, agrupamos as questões. O primeiro agrupamento foi constituído pelas questões "fechadas" em que um simples " $\mathrm{x}$ " indicava a resposta do aluno e uma alternativa excluía a outra. $\mathrm{O}$ respondente deveria assinalar apenas uma alternativa que já se encontrava bastante definida.

O segundo grupo foi composto por questões "fechadas" em que mais de uma alternativa poderia ser assinalada, mas que solicitaram ainda do aluno seu posicionamento frente a uma escala de valores, de preferências ou mesmo de usos e costumes frente a determinado fato ou tema. Foram apresentados elementos e ainda a alternativa de "outro(s). Qual(ais)?" onde poderiam ser assinaladas várias alternativas. A forma de reflexão sobre os dados apresenta natureza distinta, dando a cada aluno a oportunidade de justificar a sua resposta.

O terceiro grupo foi composto de questões discursivas sobre apreciações acerca de alguns indicadores observados pela ótica dos concluintes, com pareceres pessoais, podendo expressar sentimentos através dos quais pudemos analisar indicadores tais como: desafios, dilemas e expectativas sobre o curso de Direito. Foram questões muito importantes, para atingirmos os objetivos da pesquisa, porque deram a oportunidade ao aluno de expressar suas idéias sobre sua vida como futuro operador do Direito.

O tratamento dos dados coletados, além de uma tabulação segura, depende também de um olhar crítico do pesquisador, para a inclusão de respostas discursivas de forma confiável. O quantitativo e o qualitativo encontram-se presentes de forma que o qualitativo veio elucidar o quantitativo.

Do total de respondentes, tivemos 48 do sexo masculino e 49 do sexo feminino. Quanto à idade dos alunos, há predominância na faixa etária de 21 a 25 anos, correspondendo a 64,94\% do total, revelando que os alunos que procuram o curso são, em sua maioria, ainda bastante jovens, buscando o diploma de bacharel em Direito, para vir a exercer uma profissão condizente com o título.

Caracterizamos o concluinte da FDSM e vimos que apresenta o seguinte perfil: em sua maioria, é um aluno mais jovem que busca o curso para fazer carreira, os outros que apresentam mais idade e que já possuem um emprego, buscam o curso para assegurar a estabilidade.

Sobre as expectativas em relação ao curso em conclusão, 50,6\% dos alunos responderam que buscaram o curso para a realização de suas aspirações; 40,2\% buscaram uma formação profissional de qualidade; $7,2 \%$, melhores condições de vida; $1 \%$ obtenção de um diploma de nível superior e $1 \%$ diz não ter pensado seriamente sobre isto.

As aspirações, como já vimos, estão resumidas em 'passar em um concurso público', na busca da estabilidade financeira, isso quando esclarecem as expectativas que têm ao concluírem o curso de Direito. 'Agora é estudar para passar no exame da ORDEM e estudar para fazer um concurso' é a 
fala da maioria dos concluintes, quando perguntamos sobre o que irão fazer agora que terminaram o curso.

Entretanto vemos que a carreira do Direito não se resume a apenas "passar no concurso". Vai, além disto, porque após aprovação no concurso, a forma como o já profissional do Direito vai executar as atividades inerentes à função do cargo que venha a ocupar depende também da formação adquirida durante o curso que realizou. Os princípios norteadores de suas decisões na solução de problemas vão surgir do estudo da Lei, não friamente interpretada, mas sim, uma Lei contextualizada.

Para que isto venha a acontecer, a FDSM oportuniza o trabalho voltado ao social, em suas atividades de extensão. Encontramos alunos que participam, estando em contato com um dos maiores problemas da justiça brasileira na área penal - prisões cautelares que se prolongam além do permitido. Tal problema atinge principalmente os mais desfavorecidos que, sem vez e sem voz, ficam abandonados em um ambiente altamente nocivo, sem uma solução para seus casos.

Apesar de esta oportunidade ser oferecida pela FDSM, poucos são os alunos que se inscrevem para participar dos projetos e, ainda mais é estranho que, em momento algum de suas falas, o acadêmico se refira aos projetos desenvolvidos. Sentimos aqui que ele até gostaria de participar, mas não tem condições de fazê-lo, devido às circunstâncias de seu dia-a-dia de trabalho.

Tão logo o aluno chega à quinta série, ele se sente concluindo o curso e já apresenta suas expectativas "não vejo a hora de terminar o curso", e, no entanto, o maior percentual assinalado é o que diz respeito à formação profissional voltada para o trabalho, como nos mostra a tabela I.

Tabela I - Expectativas dos concluintes da FDSM 2010, sobre o curso de Direito realizado

\begin{tabular}{|c|c|}
\hline $\mathrm{N}^{\mathrm{o}}$ de repostas & $\%$ \\
\hline Formação teórica, voltada para a pesquisa................... 7 & 7,21 \\
\hline Formação profissional, voltada para o trabalho........... 75 & 77,34 \\
\hline $\begin{array}{l}\text { Formação acadêmica para melhorar a atividade } \\
\text { prática já desempenhada.......................................... } 7\end{array}$ & 721 \\
\hline Aquisição de cultura mais ampla.................................... 7 & 7,21 \\
\hline Outros............................................................... 1 & 1,03 \\
\hline 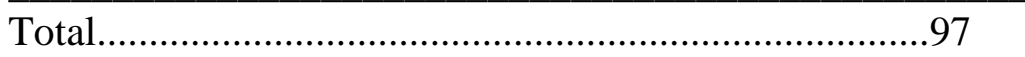 & 100,00 \\
\hline
\end{tabular}

Fonte: Questionário aplicado

Observando os dados coletados, afirmamos que 77,34\% dos alunos buscaram o curso esperando "formação profissional voltada para o trabalho", e o restante com percentuais iguais de 7,21\%, e na alternativa "outros" apenas um aluno assinalou, colocando o que esperava do curso: "uma mistura de formação acadêmica e profissional, dando um enfoque melhor para aquilo que o aluno escolhesse ser, por exemplo, advogado, juiz, promotor, etc. Dependendo da escolha seria dado um enfoque diferenciado". 
A preocupação maior do concluinte é sobre o que fazer após o término do curso. Ele precisa trabalhar e, ao mesmo tempo, precisa continuar estudando para adquirir as habilidades e competências necessárias ao desempenho "excelente" que, como profissional do Direito, deve ter para ocupar o espaço almejado. A prática é esperada pelo aluno, mas, ao mesmo tempo, quando lhe é oferecida, o aluno, principalmente do noturno, nega-se a cumprir, alegando não ter tempo para realizar as atividades práticas; trabalha e não pode faltar ao emprego para realizar a prática. Ele só apresenta a possibilidade de fazer o estágio por meio de prática simulada, por ser no horário de aula.

A tabela II demonstra a coerência dos concluintes que querem uma formação profissional voltada para o trabalho, mostrando que pretendem exercer a profissão.

Tabela II - Pretensões dos concluintes 2010, ao terminarem o curso de Direito.

\begin{tabular}{|c|c|c|c|}
\hline Sim \% & Não & $\%$ & \\
\hline Exercer a profissão para a qual está se habilitando.....77 & 24,3 & 18 & 7,9 \\
\hline Realizar estágios, ou outras atividades afins.................33 & 10,4 & 54 & 23,7 \\
\hline Cursar pós-graduação em nível de especialização....... 69 & 21,8 & 32 & 14,0 \\
\hline Cursar pós-graduação em nível de mestrado.............. 52 & 16,4 & 36 & 15,8 \\
\hline $\begin{array}{l}\text { Exercer outra profissão, diferente daquela para a } \\
\text { qual está sendo habilitado }\end{array}$ & 4,1 & 73 & 32.0 \\
\hline Realizar cursos de atualização profissional................. 73 & 23,0 & 15 & 6,6 \\
\hline
\end{tabular}

Fonte: questionário aplicado

Obs. $\mathrm{O}$ aluno assinalou mais de uma alternativa. A percentagem de cada item foi calculada pelo total de respostas.

As pretensões dos concluintes estão voltadas para a realização de atividades relacionadas com a área do Direito, e ainda para a realização de cursos, demonstrando que, apesar de o aluno não ver a hora de terminar o curso, ele assinala alternativas referentes à educação continuada. Não parar de estudar é meta do concluinte que está sentindo a necessidade de estar atualizado e preparado para enfrentar o mercado de trabalho.

Já em 1998, Escotet afirmava que: o perfil do profissional universitário de hoje pede uma formação dentro de currículos flexíveis, a capacidade de resolver problemas, adaptar-se a novos processos e tecnologias, com uma grande dose de criatividade e a firme predisposição para uma educação por toda a vida, como se depreende de estudos sobre emprego qualificado realizado em países industrializados e pela OCDE.[...] professores e alunos, serão antes de tudo aprendizes permanentes e em que os programas de estudo serão definidos em função dos novos conhecimentos e das novas tecnologias de ensino e aprendizado ${ }^{24}$

\footnotetext{
${ }^{24}$ ESCOTET, Miguel Angel, "Por um novo pacto universitário”. Revista: O Correio da Unesco, nov., 1998.
} 
Angústia e insegurança são sentimentos expressos pelo aluno que está para concluir o curso. Destacamos nos depoimentos dos alunos a preocupação com o mercado de trabalho. Após tanto "sacrifício" para terminar o curso, o aluno não vê perspectiva de futuro. Sente que a concorrência é muito grande e que a conquista de um espaço para exercer a profissão não vai ser fácil.

As idéias-força elencadas revelam que os concluintes se encontram numa fase de angústias em relação ao enfrentamento do mercado de trabalho, bastante concorrido, e ainda com o Exame da OAB para realizar.

A insegurança para exercer a profissão de advogado ou na área aparece na fala de 89,7\% dos concluintes. Percebe-se que a insegurança é colocada com base na falta de preparo, principalmente pela parte prática que é oferecida pela Faculdade, mas que o aluno, por motivos de falta de tempo ocasionada pelo trabalho, é impedido de realizar um estágio real, como deveria ou que até mesmo gostaria de ter feito.

Existe a esperança de uma minoria de concluintes que acredita estar preparado para enfrentar a profissão.

Vimos que os concluintes que já estão com os objetivos definidos realmente se encontram ansiosos para exercerem a profissão dentro da carreira jurídica. Por outro lado, encontramos alunos que se sentem angustiados, ansiosos, desesperados, despreparados, sem saber o que fazer muito apreensivos com relação ao futuro, com uma insegurança incrível e temores no enfrentamento de um mercado tão concorrido.

As angústias e os temores são grandes e demonstrados por meio de falas tais como:

Sinto imenso "frio na barriga" diante de tantas incertezas, mas cheia de fôlego para estudar e tentar concurso para magistratura.

Com muito medo do mercado lá fora; sinto-me como um garoto que nunca saiu da barra da saia da mãe.

Inseguro em relação ao mercado de trabalho.

Sinceramente? Com medo, pois o dia-a-dia lá fora é de causar pânico ao recém-formado.

Ansiosa, porém tensa por entrar neste mercado de trabalho tão concorrido.

É natural que o concluinte se sinta desta forma, porque o desconhecido amedronta, e por mais que se tenha passado pela parte prática, a insegurança ainda é o fantasma que o rodeia. $\mathrm{Na}$ Faculdade, o aluno contava com a orientação e supervisão do professor para a prática simulada ou real, movimentação de processos, garantindo-lhe a segurança de um trabalho viável.

Muitos colocam a falha do curso no descaso com que o realizaram, ou seja, a garantia do conhecimento ou das competências e habilidades que deveriam ser adquiridas durante o curso e não foram por displicência do próprio aluno que deveria ter estudado mais. 
Podemos observar que muitos dos concluintes iniciam suas exposições com palavras que revelam o quão apreensivos se encontram, mas finalizam com palavras de bastante otimismo e esperança no futuro:

Supomos que sejam também as "notórias deficiências técnico-profissionais" uma das causas da insegurança apontada pelos concluintes, além das já citadas.

Escotet disse que existe um elo perdido entre a educação e o mundo do trabalho; que a sociedade avança em ritmo tão acelerado, ultrapassando suas próprias estruturas, e que a universidade também não acompanha esse ritmo:

Da mesma forma que o restante do sistema educativo, a universidade continua ensinando a lidar com variáveis de processos estáticos, modelos de previsão baseados em séries históricas, exercícios de memória e informações deficientes. Mas a revolução do conhecimento que estamos vivendo já não corresponde a esquemas lineares e preconcebidos ${ }^{25}$.

Diante das incertezas do futuro, o concluinte também se sente inseguro: não se sente suficientemente preparado para arrostar o mercado de trabalho e a competitividade. Terminado o curso, é chegado o momento de enfrentar a realidade que se desdobra num leque de opções. A escolha amedronta, quer pela falta de experiência, quer pelo curso que não foi feito satisfatoriamente, por vários motivos, inclusive pela falta de oportunidade do aluno que trabalha, não tendo tempo suficiente para estudar e, participar de todas as atividades oferecidas pela faculdade. O certo é que todos conhecem bem o ponto de partida, mas não se sabe muito sobre o ponto de chegada.

\section{Considerações finais}

Numa atualidade marcada pela violência, pela ausência da ética e do espírito de cidadania, o advogado aparece como "tábua de salvação". Pelo seu discurso, pela sua palavra (que é sua arma), o advogado concilia, equilibra e responde aos problemas que a sociedade lhe coloca.

O operador do Direito tem por obrigação estar atento às suas atividades, para que não ocorra fato semelhante ao apresentado por Faria que diz ter encontrado publicado numa revista semanal de grande circulação o desabafo de um empresário mineiro tal como citado abaixo:

Não sou cobaia de rábula. Quantos de nós já não foram vítimas da incompetência ou desleixo daqueles que deveriam nos defender? Quando isso acontecer, quem é que nos defende dos advogados? Por isso proponho a fundação do SOS Erro Advocatício - uma organização que dê assistência às vítimas da imperícia, do erro do desmazelo desses profissionais. É uma maneira de nos unirmos contra a incompetência diplomada de alguns bacharéis ${ }^{26}$.

Por outro lado, o juramento feito pelo formando em direito ("Prometo no exercício de meu grau, respeitar sempre os princípios de honestidade, patrocinando o direito, realizando a justiça, preservando os bons costumes e nunca faltar à causa da humanidade"), mostra muito bem o que vem a ser o mister do operador do Direito. É exercer a profissão, observando a ética e o bem

\footnotetext{
${ }^{25}$ ESCOTET, Miguel Angel. Por um novo pacto universitário, 1998, p.24.

${ }^{26}$ FARIA, José Eduardo. $O$ ensino jurídico, p.47.
} 
comum “[...] nunca faltar à causa da humanidade". O aspecto social deve permear todo o curso de Direito com o objetivo de formar profissionais capazes de atuarem numa sociedade em constante conflito.

As relações do homem com seu entorno, em uma sociedade regida pela ética da individualidade e marcada pela desigualdade social, exige do profissional do Direito assumir posições inequívocas para lidar com os conflitos de todas as naturezas, inclusive e, sobretudo, conflitos de interesses que penalizam as camadas sociais mais desfavorecidas e menos organizadas para desenvolver a luta por seus direitos.

A realização desse estudo nos permitiu refletir amplamente sobre os dilemas que atingem os concluintes do curso de Direito da FDSM. A partir de um Projeto Político Pedagógico comprometido com a formação de um profissional voltado à compreensão do Direito como um campo de atuação que reúne, de forma indissociável, a competência técnica e a competência ética, cremos ser possível aliviar a angústia e os dilemas dos alunos concluintes do curso de Direito. Quem sabe, as próximas turmas que irão se formar daqui para frente já não sintam os mesmos problemas que os nossos atuais concluintes.

No entanto, bem sabemos que a luta pela inclusão no mercado de trabalho é bem árdua no Brasil de hoje. Além do mais, o concluinte do curso de Direito vive se digladiando com uma terrível contradição. Deve se colocar como alguém disposto a lutar pelo direito das pessoas na sociedade e, para tal, precisa antes lutar pelo seu próprio direito de inserir-se na profissão para produzir impactos na direção do Projeto Pedagógico de seu curso.

O concluinte enfrenta angústias, dilemas e incertezas. É instado, ao final do seu curso de graduação, a voltar o olhar para si mesmo, para seus direitos, num momento em que, deveria estar fortalecido na crença e esperança do exercício do Direito para o direito social.

O concluinte tem consciência da importância do papel do advogado como operador do Direito, podendo atuar no exercício da justiça.

No entanto, muitos deles ainda não vislumbraram o futuro e continuam sem nenhuma perspectiva, não sabem o que fazer após a conclusão do curso. Outros, já sabendo o que querem, e reconhecendo as dificuldades que poderão vir a ter, estão prontos a enfrentar o que a carreira jurídica oferece. 


\section{Referências bibliográficas}

BALZAN, Newton Cesar; LOPES, Jairo de Araújo; SORDI, Mara Regina Lemes De. $O$ concluinte/2000 e sua visão de universidade, vida universitária e qualidade de ensino: conhecer para aprimorar. Pontifícia Universidade Católica de Campinas - PUC-Campinas, Série Acadêmica, no 14. 2000.

BASTOS, Aurélio Wander. O ensino jurídico no Brasil e as suas personalidades históricas -uma recuperação de seu passado para reconhecer seu futuro, OAB: 170 anos de cursos jurídicos no Brasil. Brasília, DF: Printer, 1997. 213 p.

BRASIL, Lei de Diretrizes e Bases da Educação Nacional, Lei no 9.394, de 20/12/9.

BRASIL, Conselho Federal da Ordem dos Advogados do Brasil, OAB. Ensino jurídico: balanço de uma experiência, Brasília, DF, LID Gráfica, 2000. P. 245.

BRASIL, Constituição da República Federativa do Brasil: promulgada em 5 de outubro de 1988, 29. ed., São Paulo, Saraiva, 2002. P.349.

BRASIL, Portaria n ${ }^{\circ} 1.886$ de 30 de dezembro de 1994, MEC, fixa as diretrizes curriculares e o conteúdo mínimo do curso jurídico, publicada no Diário Oficial da União- DOU, Brasília, em 4 de janeiro de 1995.

BRASIL, Resolução CNE/CES no 9, de 29 de setembro de 2004, Institui as Diretrizes Curriculares do Curso de graduação em Direito e dá outras providências, publicada no Diário Oficial da União, Brasília, $1^{\circ}$ de outubro de 2004, Seção 1.P.17.

CURY, Var de A. R., "O currículo e a medida do social: estudo de um curso de Direito contribuição para avaliação institucional”. In: DIAS SOBRINHO, José; BALZAN, Newton Cesar (orgs) Avaliação institucional: teoria e experiências, 2.ed. São Paulo: Cortez, 2000. P.180.

ESCOTET, Miguel Angel, "Por um novo pacto universitário". Revista: O Correio da Unesco, nov., 1998.

FARIA, José Eduardo "O ensino jurídico", In OAB, Conselho Federal da Ordem dos Advogados do Brasil, OAB Ensino Jurídico: Diagnóstico, perspectivas e propostas, Brasília, DF, Printer, 1996a, 316 p. 
GUSMÃO, Paulo Dourado de. Introdução ao estudo do direito. 19. ed. Rio de Janeiro: Forense, 1996. $476 \mathrm{p}$.

HERKENHOFF, João Batista. OAB - "Ensino jurídico". In OAB, Conselho Federal da Ordem dos Advogados do Brasil. OAB Ensino Jurídico: Diagnóstico, perspectivas e propostas. Brasília, DF: Printer, 1996. 316 p.

MARIOSA, Maria Aparecida Silva. Perfil de ingressantes /2002. Pesquisa não publicada, 2002.

MELO FILHO, Álvaro. "Currículo jurídico - um modelo atualizado", In OAB, Conselho Federal da Ordem dos Advogados do Brasil. OAB Ensino Jurídico: Diagnóstico, perspectivas e propostas. Brasília, DF: Printer, 1996ª P.316.

MORIN, Edgard. Os sete saberes necessários à educação do futuro, Trad. Catarina Eleonora F. da Silva e Jeanne Sawaya. São Paulo: Cortez, 2000. 118 p.

RIBEIRO JÚNIOR, João. A formação pedagógica do professor de Direito: Conteúdos e alternativas metodológicas para a qualidade do ensino do Direito. Campinas, SP: Papirus, 2001. $80 \mathrm{p}$.

REVISTA DO PROVÃO 2002 - Brasília: Instituto Nacional de Estudos e Pesquisas Educacionais, 2002, Anual. ISSN 1413-7720

RODRIGUES, Horácio Wanderley; JUNQUEIRA, Eliane Botelho. Ensino do direito no Brasil. Florianópolis: Fundação José Boiteux, 2002. 559 p. 